International Journal of Chemical Engineering Research.

ISSN 0975 - 6442 Volume 3, Number 1 (2011), pp. 71-80

(C) Research India Publications

https://dx.doi.org/10.37622/IJChER/3.1.2011.71-80

\title{
Review of Gas Holdup Characteristics of Bubble Column Reactors
}

\author{
Santosh Walke ${ }^{1 *}$ and Vivek Sathe ${ }^{2}$ \\ ${ }^{1}$ Department of Chemical Engineering, \\ Bharati Vidyapeeth College of Engineering, Navi Mumbai, India. \\ ${ }^{2}$ Department of Chemical Engineering, \\ Dr. Babasaheb Ambedkar Technological University, Lonere, Raigad, India \\ *Corresponding Author
}

\begin{abstract}
Gas-liquid bubble columns are used extensively in the process industries. The gas-liquid two phase flow prevailing in this type of process equipment is extremely complex, inherently unsteady and dominated by phenomena with widely varying time-and length-scales. It is for this reason that many important fluid dynamical aspects of gas-liquid bubble columns are still poorly understood and difficult to predict a priori. This paper aims to contribute to our understanding of the gas holdup characteristics of gas-liquid bubble column reactors by reviewing recently published studies. Three-phase bubble column reactors are widely employed in reaction engineering, i.e. in the presence of a catalyst and in biochemical applications where microorganisms are utilized as solid suspensions in order to manufacture industrially valuable bioproducts. Investigation of design parameters characterizing the operation and transport phenomena of bubble columns have led to better understanding of the hydrodynamic properties, heat and mass transfer mechanisms and flow regime characteristics ongoing during the operation. Moreover, experimental studies are supported with computational fluid dynamics (CFDs) simulations and developed mathematical models to describe better the phenomena taking place in a bubble column reactor. This review focuses on bubble column reactors, their description, design and operation, application areas, fluid dynamics and regime analysis encountered and parameters characterizing the operation are presented together with the findings of published studies. This work is the extension of work done by Kuntlu O Ulgen et al.,(2005).
\end{abstract}

Keywords: Bubble column; Porous sparger; Gas holdup; Bubble size; Coalescence. 


\section{Introduction}

Bubble column reactors belong to the general class of multiphase reactors which consist of three main categories namely, the trickle bed reactor (fixed or packed bed), fluidized bed reactor, and the bubble column reactor. A bubble column reactor is basically a cylindrical vessel with a gas distributor at the bottom. The gas is sparged in the form of bubbles into either a liquid phase or a liquid-solid suspension. These reactors are generally referred to as slurry bubble column reactors when a solid phase exists. Bubble columns are intensively utilized as multiphase contactors and reactors in chemical, petrochemical, biochemical and metallurgical industries [1]. They are used especially in chemical processes involving reactions such as oxidation, chlorination, alkylation, polymerization and hydrogenation, in the manufacture of synthetic fuels by gas conversion processes and in biochemical processes such as fermentation and biological wastewater treatment [2,3]. Some very well known chemical applications are the famous Fischer- Tropsch process which is the indirect coal liquefaction process to produce transportation fuels, methanol synthesis, and manufacture of other synthetic fuels which are environmentally much more advantageous over petroleum-derived fuels [1].

Bubble columns are a class of multiphase reactors, which are used for carrying out reactions and gas-liquid mass transfer operations. They are characterized by the fact that the gas is dispersed in the liquid phase. Increasing interest in the bubble column as a reactor in the various fields like chemical, petrochemical, petroleum is mainly due to its simple structure, absence of moving parts, good heat and mass transfer characteristics and low energy input requirements.

Bubble columns can be divided into three regions. In the first region near the sparger, the behaviour and properties of the bubbles are determined by the sparger design and the gas flow rate. In the second region, bubbles occupy most of the column volume and there the properties are determined by the liquid flow intensity and the flow pattern. In the third region, bubbles coalesce and escape from the top surface.

Bubble column reactors owe their wide application area to a number of advantages they provide both in design and operation as compared to other reactors. First of all, they have excellent heat and mass transfer characteristics, meaning high heat and mass transfer coefficients. Little maintenance and low operating costs are required due to lack of moving parts and compactness. The durability of the catalyst or other packing material is high [1]. Moreover, online catalyst addition and withdrawal ability and plug-free operation are other advantages that render bubble columns as an attractive reactor choice [3]. Due to their industrial importance and wide application area, the design and scale-up of bubble column reactors, investigation of important hydrodynamic and operational parameters characterizing their operation have gained considerable attention during the past 20 years.

Recent research with bubble columns frequently focuses on the following topics: gas holdup studies $[4,5,6,7]$, bubble characteristics $[3,8,10]$, flow regime investigations and computational fluid dynamics studies [1,11,12,13,14], local and average heat transfer measurements, and mass transfer studies. The effects of column dimensions, column internals design, operating conditions, i.e. pressure and temperature, the effect of superficial gas velocity, solid type and concentration are 
commonly investigated in these studies. Many experimental studies have been directed towards the quantification of the effects that operating conditions, slurry physical properties and column dimensions have on performance of bubble columns [16]. Although a tremendous number of studies exist in the literature, bubble columns are still not well understood due to the fact that most of these studies are often oriented on only one phase, i.e. either liquid or gas. However, the main point of interest should be the study of the interaction between the phases, which are in fact intimately linked [17].

More specifically, in order to design bubble column reactors, the following hydrodynamic parameters are required: specific gas-liquid interfacial area, axial solids dispersion coefficients, sauter mean bubble diameter, axial dispersion coefficients of the gas and liquid, overall heat transfer coefficient between slurry and immersed heat transfer internals, mass transfer coefficients for all the species, gas holdups, physicochemical properties of the liquid medium. In order to estimate these design parameters for the system, experimental studies benefit from specialized measuring devices and accessories. The gas flow into the column is measured via rotameter and the superficial gas velocity is adjusted. The gas is distributed by a gas distributor, which has different alternatives such as ring type, perforated plate or arm distributor. An electric heater can be installed to maintain constant temperature in the column. The pressure measurement system may contain liquid manometers or pressure transducers (pressure transmitters). Pressure measurements are used to estimate gas holdup in the system. Thermocouples are used wherever temperature variation is needed to be recorded. Heat flux sensors may be used to estimate the heat flux and to measure the corresponding heat transfer coefficients between the heated immersed object and slurry or the slurry and wall. For better control and adjustment, the equipments are usually accompanied by PID controllers. Data acquisition systems may be utilized for instantaneous parameter investigations, for instance for recording the pressure fluctuations and estimation of instantaneous gas holdups and bubble properties.

\section{Bubble column reactors: concepts and published work}

As far as published studies are concerned, the main interest is concentrated on design and scale-up, fluid dynamics and regime analysis and characteristic parameters, especially gas holdup, bubble characteristics, mass transfer coefficient and heat transfer coefficient. In this section, together with these concepts, the effects of superficial gas velocity, liquid properties, operating conditions, column dimensions, gas distributor design, solid type and concentrations are presented.

\section{Gas holdup}

Gas holdup is a dimensionless key parameter for design purposes that characterizes transport phenomena of bubble column systems [4]. It is basically defined as the volume fraction of gas phase occupied by the gas bubbles. Likewise it is possible to 
characterize the liquid and solid phase holdups as the volume fraction of liquid and solid phases, respectively. All studies examine gas holdup because it plays an important role in design and analysis of bubble columns. As reported by $\mathrm{Li}$ and Prakash [9], in a three-phase slurry bubble column, the static pressure drop along the bed height can be expressed as

$$
\Delta \mathrm{P}=\left(\rho_{\mathrm{g}} \mathrm{e}_{\mathrm{g}}+\rho_{1} \mathrm{e}_{1+} \rho_{\mathrm{s}} \mathrm{e}_{\mathrm{s}}\right) \mathrm{g} \Delta \mathrm{H}
$$

In the above equation, $e_{g}, e_{1}$ and $e_{s}$ are the volume fractions of gas, liquid and solid phases, respectively. $e_{g}$ is also named as the gas holdup, $g, r$ and $\mathrm{DH}$ are the gravitational acceleration, the density and height difference between the transducers, respectively. The subscripts $\mathrm{g}, 1$ and $\mathrm{s}$ stands for gas, liquid and solid phases. By proper substitutions, starting with Eq. (1), one can factor out the gas holdup as

$$
e_{g}=1-\frac{1}{g\left\{\left(\rho_{2} \varphi_{2}\right)+\left(\rho_{s} \varphi_{s}\right)\right.} \frac{\Delta P}{\Delta H}
$$

Eq. (2) can be directly applied for estimation of gas holdup in a slurry bubble column. The most widely used technique in estimating gas holdup is the pressure profile method which is based on measuring the static pressure at two or more points along the column using manometers or more recently pressure transducers and thus obtaining the pressure drop, DP, along the bed [22,24,26,27].

The spatial variation of gas holdup, i.e gas holdup profile is another important factor which gives rise to pressure variation and thus liquid recirculation. Since liquid recirculation plays an important role in mixing and heat and mass transfer, predictions of radial gas holdup profiles would lead to better understanding of these phenomena and thus more reliable bubble column scale-up. The magnitude of gas holdup radial diameter, physical properties of the system and operating conditions [21]. There exist various correlations in literature in order to predict the gas holdup in both two-phase bubble columns and three-phase slurry bubble columns It is reported that the basic factors affecting gas holdup are: superficial gas velocity, liquid properties, column dimensions, operating temperature and pressure, gas distributor design, solid phase properties. In the subsections below, the findings of various studies on the effects of these factors are presented.

\section{Superficial gas velocity}

Superficial gas velocity is the average velocity of the gas with increasing superficial gas velocity $[3,9,16,18,19,20,25,28,29]$. Although the systems investigated in these studies are quite different from each other, all conclude that the gas holdup increases with increasing superficial gas velocity. This increase has been found to be proportional to superficial gas velocity in the bubbly flow regime [30,31]. For the churn-turbulent regime, the effect of superficial velocity on gas holdup is less pronounced [31,32]. Hyndman et al. [19] analysed the contribution of small and large bubbles to overall holdup via equations. The authors pointed out that in the churnturbulent regime, as the superficial velocity increases the overall holdup increases due to the large bubble holdup increase. The contribution of small bubbles to overall 
holdup is constant and equal to the transition holdup, i.e. it does not increase with increasing superficial velocity. But the large bubble holdup increases with increasing superficial velocity, leading to the increase of the overall holdup. However, in bubbly flow, small bubble holdup is not constant but changes significantly as the superficial velocity is changed. Recently investigation of effect of gas velocity on gas holdup profiles in foaming liquids. They observed that the superficial gas velocity has a large influence on radial holdup profile at high foaming agent concentrations.

\section{Liquid phase properties}

The liquid phase property has an impact on bubble formation and/or coalescing tendencies and hence is an important factor affecting gas holdup. An increase in liquid viscosity results in large bubbles and thus higher bubble rising velocities and lower gas holdup [33]. It is also reported that adding a small amount of a surface acting material (surfactant) to water, results in significantly higher gas holdup values. Moreover, the presence of electrolyte or impurities also increases gas holdup [26,34]. Ozturk et al. [35] investigated the gas holdups in various organic liquids and they reported that in several mixed and adjusted mixtures, the gas holdups were higher as compared to pure liquids with the same properties (surface tension, density, viscosity). They also concluded that the gas holdups were higher with high density gases. Veera et al. [7] investigated gas holdup in the presence of foaming liquids and concluded that the effect of foaming agent concentration on holdup profiles depended upon the sparger design, column aspect ratio and superficial gas velocity. The authors also claimed that the gas holdup profiles were flatter at higher foaming agent concentrations. Recently, Tang and Heindel [6] suggested that regular tap water, which is the most frequently used liquid in bubble columns, might cause

\section{Operating conditions}

The effect of operating pressure and temperature on gas holdup of bubble columns were also investigated in many studies [23,27]. It is commonly accepted that elevated pressures lead to higher gas holdups. Empirical correlations have been proposed for gas holdup in bubble columns operated at high pressure and temperature [27]. Luo et al. [4] carried out experiments at about 5.6 MPa, to investigate the effect of pressure on the hydrodynamics of a slurry bubble column and found that gas holdup increases with pressure and the pressure effect is more pronounced in higher concentration slurries. In the study of Deckwer et al. [25] typical high pressure conditions of the Fischer- Tropsch process were investigated, i.e. 400-1100 kPa. However, they concluded that pressure had no significant effect on holdup. The operating temperature is another important factor to be discussed. Although most studies conclude that the temperature effect is not so significant, some disagree with this argument. For instance, Deckwer et al. [25] reported a decrease in the gas holdup with increasing temperature up to a certain temperature value and the gas holdup had reached a constant value with further increase of temperature. An interesting point in this study was that these results were obtained in a small diameter column, suggesting that in larger diameter columns, such a temperature effect would not be observed. Thus, the authors attributed this trend to possible "wall effects" in the small diameter 
column. Saxena et al. [28] investigated two and three-phase bubble columns within a 297-343 K temperature range and they found out such a temperature dependence of gas holdup only in the two-phase system.

\section{Column dimensions}

The effect of column diameter and height on hydro dynamics is also widely investigated in literature. Shah et al. [2] reported that in bubble columns, the effect of column size on gas holdup is negligible when the column diameter is larger than 10-15 cm. Luo et al. [4] reported that the influence of the column height is insignificant if the height is above 1-3 $\mathrm{m}$ and the ratio of the column height to the diameter (aspect ratio) is larger than 5. Possible wall effects brought about by the use of small diameter columns $(310 \mathrm{~cm})$ were also pointed out [25,28]. It was reported that the gas holdup was not highly dependent on column diameter when the column diameter was larger than $10 \mathrm{~cm}$, as long as mixing was well maintained. Daly et al. [29] found that the holdup is independent of the column height. Additionally, though not so significant, they obtained some differences in holdup with variation of the column diameter. It was observed that the holdup in small diameter columns. The effect of column dimensions on gas holdup in foaming systems has not received significant attention in literature. Pino et al. [16] observed no appreciable differences in the gas holdup of foaming systems between columns of 10 and $29 \mathrm{~cm}$ in diameter, in the semibatch mode of operation. It was also reported that the effect of column height was insignificant for height to diameter ratios between 3 and 12. At high gas velocities when foaming occurred, both column height and diameter had no effect on gas holdup, whereas, for non-foaming systems and for column diameters up to $15 \mathrm{~cm}$, gas holdup was found to decrease with increasing column diameter. According to the two-phase model developed by Krishna et al. [18,23] the effect of column diameter on gas holdup should be separately analyzed for small and large bubble gas holdups. It was found out that the small bubble gas holdup is independent of column diameter, while the large bubble gas holdup decreased with increasing column diameter. As a result the overall holdup is reported to decrease with increasing column diameter due to large bubble holdup. The dependence of large bubble holdup on column diameter was described by the following correlation proposed by Krishna et al. [18]:

$$
e_{b} \lg =\alpha_{2} \frac{1}{D_{T}^{N}}\left(V_{g}-V_{d f}\right)^{0.58}
$$

Here, $e_{b} l_{g}$ is the holdup due to large bubbles which constitute, $\alpha$ KrishnaEllenberger fit parameter

\section{Gas sparger}

Gas sparger type is an important parameter that can alter bubble characteristics which in turn affects gas holdup values and thus many other parameters characterizing bubble columns. The sparger used definitely determines the bubble sizes observed in the column. Small orifice diameter plates enable the formation of smaller sized 
bubbles. Some common gas sparger types that are used in literature studies are perforated plate, porous plate, membrane, ring type distributors and arm spargers. Bouaifi et al. [5] stated that, the smaller the bubbles, the greater the gas holdup values. Thus, they concluded that with small orifice gas distributors their gas holdup values were higher. In another study by Luo et al. [4], gas holdup was found to be strongly affected by the type of gas distributor. The effect was more pronounced especially for gas velocities below $6 \mathrm{~cm} / \mathrm{s}$. Schumpe and Grund et al., [20] worked with perforated plate and ring type gas spargers. They concluded that with ring type distributor, the total holdup was smaller. They also added that the small bubble holdup showed a gradual increase with increasing superficial velocity with ring type sparger. Another conclusion about the type of spargers was that the contributions of both small and large bubbles to gas velocity were lower with ring sparger as compared to the perforated plate.

\section{Solid concentration}

The effect of solid concentration and particle size on gas holdup has been investigated by a number of researchers Several researchers concluded that an increase in solids concentration generally reduced the gas holdup [16,18,25,31,34]. Sada et al. [34] also reported that for low solids loading $(<5$ vol.\%), the behaviour of the slurry bubble column is close to that of a solid-free bubble column. Contrarily, Kara et al. [31] found a strong dependence of gas holdup on solids concentration at low solids concentrations.

Many studies have been conducted to investigate the effects of particle size on gas holdup as well [31,34]. The influence of particle size has been found to depend on a number of factors including flow regime, gas velocity, liquid properties and slurry concentration. It is generally reported that addition of solids to a two-phase system decreases the holdup $[9,16,18,28,33]$. For a fixed gas velocity and solid concentration, increasing the solid diameter also decreased the holdup and this effect of particle size was more. On the other hand, large bubble holdup is reported to be independent of solids concentration. Based on this, Krishna et al. [18] proposed a correlation for small bubble holdup showing its dependence on solids concentration:

$$
e_{d f}=e_{d f, 0}\left(1-\frac{0.7}{e_{d f, 0}} \varphi_{s}\right)
$$

Here, $e_{d f}$ is the dense-phase gas holdup (small bubble holdup), $e_{d f, 0}$ the gas holdup for only gas-liquid system, and $\mathrm{f}_{\mathrm{s}}$ is the solids volume fraction.

There are very few studies in literature on the use of actual cells in slurry bubble columns as the solid phase, in contrast to many studies which report the decrease of gas holdup with solids concentration. In the study of Prakash et al. [3], holdup was observed to increase with solids concentration. During the operation of the column, it was observed that a foam layer was formed, at the top of the dispersion, due to the presence of surface active agents like alcohols, proteins, etc. in the solutions used. Increasing the yeast concentration just increased the surfactant concentration which in turn increased the foam bed and resulted in higher gas holdup values. 


\section{Summary of gas holdup studies}

Summarizing the studies discussed so far about gas holdup it can be said that, the gas holdup increases with increasing gas velocity and operating pressure; whereas it decreases with increasing liquid viscosity and solid concentration. Adding a surface active reagent into the slurry increases the holdup. In bubble columns, the effect of column size on gas holdup is negligible when the column size on gas holdup is negligible when the column diameter is larger than $10-15 \mathrm{~cm}$ and the height is above 1-3 $\mathrm{m}$, in other words with height to diameter ratios (aspect ratio) larger than 5. At low gas velocities, gas holdup depends on the number, pitch and diameter of the orifice holes. For orifice diameter larger than $1 \mathrm{~mm}$, the effect of orifice diameter becomes insignificant.

\section{References}

[1] Degaleesan S, Dudukovic M, Pan Y. Experimental study of gas-induced liquidflow structures in bubble columns. AIChE J 2001;47:1913-31.

[2] Shah YT, Godbole SP, Deckwer WD. Design parameters estimations for bubble column reactors. AIChE J 1982;28:353-79.

[3] Prakash A, Margaritis A, Li H. Hydrodynamics and local heat transfer measurements in a bubble column with suspension of yeast. Biochem Eng $\mathbf{J}$ 2001;9:155-63.

[4] Luo X, Lee DJ, Lau R, Yang G, Fan L. Maximum stable bubble size and gas holdup in high-pressure slurry bubble columns. AIChE J 1999;45:665-85.

[5] Bouaifi M, Hebrard G, Bastoul D, Roustan M. A comparative study of gas holdup, bubble size, interfacial area and mass transfer coeffi-cients in stirred gas-liquid reactors and bubble columns. Chem Eng Process 2001;40:97-111.

[6] Tang C, Heindel TJ. Time-dependent gas holdup variation in an air- water bubble column. Chem Eng Sci 2004;59:623-32.

[7] Veera UP, Kataria KL, Joshi JB. Effect of superficial gas velocity on gas holdup profiles in foaming liquids in bubble column reactors. Chem Eng $\mathrm{J}$ 2004;99:53-8.

[8] Essadki H, Nikov I, Delmas H. Electrochemical probe for bubble size prediction in a bubble column. Exp Therm Fluid Sci 1997;14:243-50.

[9] Li H, Prakash A. Influence of slurry concentrations on bubble population and their rise velocities in three-phase slurry bubble column. Powder Technol 2000;113:158-67.

[10] Lapin A, Paaschen T, Junghans K, Lu“bbert A. Bubble column fluid dynamics, flow structures in slender columns with large-diameter ring-spargers. Chem Eng Sci 2002;57:1419-24.

[11] Ruzicka MC, Zahadnik J, Drahos J, Thomas NH. Homogeneousheterogeneous regime transition in bubble columns. Chem Eng Sci 2001;56:4609-26. 
[12] Buwa VV, Ranade VV. Dynamics of gas-liquid flow in a rectangular bubble column: experiments and single/multi-group CFD simulations. Chem Eng Sci 2002;57:4715-36.

[13] Michele V, Hempel DC. Liquid flow and gas holdup-measurement and CFD modeling for two-and-three-phase bubble columns. Chem Eng Sci 2002;57:1899-908.

[14] Dhotre MT, Ekambara K, Joshi JB. CFD simulation of sparger design and height to diameter ratio on gas hold-up profiles in bubble column reactors. Exp Therm Fluid Sci 2004;28:407-21.

[15] Thorat BN, Joshi JB. Regime transition in bubble columns: experi-mental and predictions. Exp Therm Fluid Sci 2004;28:423-30.

[16] Pino LZ, Solari RB, Siuier S, Estevez LA, Yepez MM, Saez AE. Effect of operating conditions on gas holdup in slurry bubble columns with a foaming liquid. Chem Eng Commun 1992;117:367-82.

[17] Lefebvre S, Guy C. Characterization of bubble column hydrodynamics with local measurements. Chem Eng Sci 1999;54:4895-902.

[18] Krishna R, De Stewart JWA. Ellenberger J, Martina GB, Maretto C. Gas holdup in slurry bubble columns: effect of column diameter and slurry concentrations. AIChE J 1997;43:311-6.

[19] Hyndman CL, Larachi F, Guy C. Understanding gas-phase hydro-dynamics in bubble columns: a convective model based on kinetic theory. Chem Eng Sci 1997;52:63-77.

[20] Schumpe A, Grund G. The gas disengagement technique for studying gas holdup structure in bubble columns. Can J Chem Eng 1986;64:891-6.

[21] Wu Y, Ong BJ, Al-Dahhan MH. Predictions of gas hold-up profiles in bubble column reactors. Chem Eng Sci 2001;56:1207-10.

[22] Miller DN. Gas holdup and pressure drop in bubble column reactors. Ind Eng Chem Process Des Dev 1980;19:371-7.

[23] Krishna R, De Stewart JWA, Hennephof DD, Ellenberger J, Hoef-sloot HCJ. Influence of increased gas density on hydrodynamics of bubble column reactors. AIChE J 1994;40:112-9.

[24] Fan LS, Matsuura A, Chern SS. Hydrodynamic characteristics of a gas-liquidsolid fluidized bed containing a binary mixture of par-ticles. AIChE J 1985;31:1801-10.

[25] Deckwer WD, Louisi Y, Zaidi A, Ralek M. Hydrodynamic properties of the Fisher-Tropsch slurry process. Ind Eng Chem Process Des Dev 1980;19:699_ 708.

[26] Hikita H, Asal S, Tanigawa K, Segawa K, Kitao M. Gas holdup in bubble column. Chem Eng J 1980;20:59-67.

[27] Reilley IG, Scott DS, De Bruijin T, Jain A, Piskorz J. A correlation for gas holdup in turbulent coalescing bubble columns. Can J Chem Eng 1986;64:70517.

[28] Saxena SC, Rao NS, Saxena AC. Heat-transfer and gas-holdup studies in a bubble column: air-water-glass bead system. Chem Eng Commun 1990;96:3155. 
[29] Daly JG, Patel JG, Bukur DB. Measurement of gas holdups and sauter mean bubble diameters in bubble column reactors by dynamic gas disengagement method. Chem Eng Sci 1992;47:3647-54.

[30] Lockett MJ, Kirkpatrick RD. Ideal bubbly flow and actual flow in bubble columns. Trans Inst Chem Eng 1975;53:267-73.

[31] Kara S, Kelkar BG, Shah YT, Carr NL. Hydrodynamics and axial mixing in a three-phase bubble column. Ind Eng Chem Process Des Dev 1982;21:584-94.

[32] Koide K, Takazawa A, Komura M, Matsunga H. Gas holdup and volumetric liquid phase mass transfer coefficient in solid-suspended bubble column. J Chem Eng Jpn 1984;17:459-66.

[33] Li H, Prakash A. Heat transfer and hydrodynamics in a three-phase slurry bubble column. Ind Eng Chem Res 1997;36:4688-94.

[34] Sada E, Katoh S, Yoshil H. Performance of the gas-liquid bubble column in molten salt systems. Ind Eng Chem Process Des Dev 1984;23:151-4.

[35] Ozturk SS, Schumpe A, Deckwer WD. Organic liquids in a bubble column: holdups and mass transfer coefficients. AIChE J 1987;33:1473-80

[36] Nigar Kantarci, Fahir Borak, Kutlu O. Ulgen. Review of Bubble Column Reactor, Process Biochemistry 40 (2005), 2263-2283 